\title{
Pha Khao Phuluang "A Restoration Project" Case Study-Forest Exploits of the Past and Present RFD Can Fix It!-Develop Strong Organizational and Community Bases-Forest Restored!
}

\author{
Auschala Chalayonnavin ${ }^{1} \&$ Sirirat Choonhaklay ${ }^{1}$ \\ ${ }^{1}$ Faculty of Social Science and Humanities, Mahidol University, Bangkok, Thailand \\ Correspondence: Auschala Chalayonnavin, Faculty of Social Science and Humanities, Mahidol University, \\ Bangkok, Thailand. E-mail: auschala_c@hotmail.com
}

$\begin{array}{cc}\text { Received: August 18, } 2014 & \text { Accepted: October 13, } 2014 \quad \text { Online Published: December 20, } 2014 \\ \text { doi:10.5539/ass.v11n2p124 } & \text { URL: http://dx.doi.org/10.5539/ass.v11n2p124 }\end{array}$

\begin{abstract}
The forests of Thailand have been depleted at an alarming rate over the past few decades in Pha Khao Phuluang due to illegal encroachment and deforestation. This situation has not been helped by incoherent and uncoordinated government policies regarding natural resources and agricultural expansion. As a result, the Royal Forestry Department (RFD), as the direct agency responsible for the forestry area maintenance and governmental policy implementation, cannot address the problems effectively. This paper attempts to examine problems regarding the Royal Forestry Department's policy implementation with a mission to improve the state agencies so they can sustain Thai national resources in a more effective and efficient way. The research uses mixed method analysis. The priority qualitative data is gathered by in-depth interview with 3 groups of executives who are directly involved with illegal deforest suppression and repression. The minor qualitative data is gathered from literature review. Then, a triangulation technique is used for data verification combining multiple observers including experts, literature reviews and officers using Delphi analysis. The proposed solutions I outline are as follows: 1. In order to fix the problem the government must grant additional time for community rehabilitation and recovery from the crisis so that they may secure new living space and for economic and social adjustments within the community 2. The Royal Forestry Department officers must be trained and educated regarding their roles, responsibilities and authorities under the nation's laws. 3. At this point the government should offer policies in order to support economic and social changes of the community as a supplementary opportunity for people to live their lives under the ecosystems conservation context.
\end{abstract}

Keywords: state agencies reforms, resources conservation, royal forest, Pha Khao-Phuluang, Thailand, implementation, enforcement, parsons theory

\section{Introduction}

\subsection{Introduce the Problem}

The current situation of forest resources in Thailand has several problems of illegal logging and progressive deforestation aimed for wood utilization and shifting cultivation. Especially over forest reservation areas such as, Reservation Park, National Park and Wildlife Sanctuaries Park that remain deteriorated by intruders respectively over the last fifteen years. Particularly in Pha Khao Phuluang Forest, the official forest reservation area situated in Amphoe Wangnamkeaw, in Nakhon Ratchasima Province. The problem was derived from an issue in the policy implementation and law enforcement process. Authorized officers neglected to enforce policy and law in the past which caused the national forest trading problems, which lead to the devastation of the forest resource. In particular, the definition of the Forest Conservation Area was emphasized by forestry officer in laws called Command and Control, which they did not practice in their obligatory approach (FAO, 1980). All existing issues within the Royal Forestry are caused by the inconsistencies between government policy enforcement and socio-economic conditions within the community (Lokeniyom, 2008). The Royal Forest Department (RFD) has no long-term policy planning that can support tourism within the district in the first phase. The department gave Agricultural Land Reforms Office's title-deeds (ALRO4-01) to others areas that should have been designated as public watershed (Tongkham \& Huttasarn, 2011). Government plans to recall property would revoke rights from the community thus damaging the locals socio-economic standing; possibly leading to violence, anti-government 
protests, and creating general instability within the social system (Tongkham \& Huttasarn, 2011).

\subsubsection{Research Problems}

1) What current procedures does RFD employ for law enforcement to protect and preserve the forest in Pha Khao Phuluang?

2) What are the significant barriers and problems that RFD experience regarding law enforcement in terms of protecting and preserving the forest in Pha Khao Phuluang?

3) What concepts or principles are used to improve patterns of law enforcement in order to protect and preserve the forests in Pha Khao Phuluang under the context of RFD including management tools?

\subsubsection{Research Objectives}

1) To study the process of RFD's law enforcement on forest preservation in Pha Khao Phuluang.

2) To analyze the current situation of the problems of RFD's law enforcement officers in the field of forest protection in Pha Khao Phuluang.

3) To propose possible approaches in order to improve RFD's law enforcement for forest preservation in Pha Khao Phuluang.

\subsection{Importance of the Problem}

The study on the current situation of the Royal Forest Department's law enforcement officers in Pha Khao-Phuluang area is absolutely necessary as it is discerning to correct the injustice of forest encroachment issues and to amend the ambiguous regulation involved on the policy implementation including some deceptive practical measures which will lead its' airing mechanism in order to develop the Royal Forest Department in the very near future

\subsection{Relevant Scholarship}

Pha Khao Phuluang Forest, an official forest reservation area situated in Amphoe Wangnamkeaw in Nakhon Ratchasima province is recognized as the second largest reservationpark in Thailand with an approximate area of 706243 rais (National Bureau, 2013). Pha Khao Phuluang is the most fertile forest covered area in Thailand's northeast and is presently occupied by agricultural and tourism industrial expansion (Wanapitak, 2013). The bureau discovered that shifting cultivation and the timber industry are leaving the remaining areas filled with stumps and empty spaces (Tracking Department of Forestry, 2013). Soon after, people from both inner and outer areas including Northeast provinces such as Nakorn Ratchasima, Surin, Buriram, Ubon Ratchathani and outer regions such as Bangkok, immigrated to Pha Khao Phuluang for agricultural cultivation. Using land degrading processes threatening natural plant species and ecological communities through soil erosion as the soil degrades and agricultural crop threatened, most villagers sell the areas to capitalist and elite. This scenario is a critical problem for street level officers to stop the natural resource crime (Tracking Department of Forestry, 2013). Presently Pha Khao Phuluang has countless vacation resorts and hotels especially in the Wangnamkeaw district. The Royal Forest Officer recently discovered approximately 500 lodges were constructed within the area by the Thais' elite. This unauthorized construction adds to the compounding forest reserve encroachment issues. To this day a colossal 430,000 rais has been encroached upon in Pha Khao Phuluang (Tracking Department of Forestry, 2013).

While addressing the Thai forest encroachment situation in regards to public policy and policy implementation in 1961 Thailand enacted the National Economic and Social Development Plan Volume 1 with an intention to restore forests by setting up disciplines to save 50 percent of the country's area for forest conservation. According to its intention, RFD was enacted by rule to increasingly announce the forest reservation area in order to complete the 1964 National Forest Act Mission. Because zoning regulations were implemented with time limits, the outcome of the National Forest map was completed without the actual measurement of the reference area. Consequently, this regulatory measure unintentionally made people who are living in those areas a part to forest encroachment crimes by default, leading to the state to set specific measurements to the area resolution (Lokeniyom, 2008).

In 1993, Thai population grew to more than 65 million, highlighting the problem of land use management, resulting in many Thai people becoming pioneers to forest reservation spaces. The more people involved in national land usage, the more they empowered themselves in their political enhancement. Acting on this the government attempted to enact waivers with the intent to diffuse problems and its expansion. The first attempt was the Economic and Social Development Plan Volume no 2, which reduced a forest reservation area from 50 percent to 40 percent of the total country area in order to allow some extent of national forest area to be specified 
as an economic zone (37.6 million acres). Designated by the government, RFD hosted to be one of the policy implementation agencies that differentiate between the areas for conservation and the degraded forest area for agricultural cultivation (FAO, 2003). RFD was authorized at its discretion with time limits to conduct the implementation plan in the first phase. Therefore, zoning took place without an actual space assessment, as a result some spaces that were not suitable for agriculture were included into the reformation area. When the land allocation policy was enacted, most forest concessionaires did not comply with the rule. Approximately (70 percent) were persistently altering the concessionary holders in Pha Khao Phuluang which most were unable to get a title because the area was state owned. Therefore, people who are now taking advantage of space in Pha Khao Phuluang were actually national offenders (Tracking Department of Forestry, 2013).

As previously stated, problems and miscommunication originated from poor policy implementation and the enforcement of the laws. Forest duty officers neglected to enforce laws and were the direct cause of trading and the invasion of forest resources. In particular, Command and Control laws for the conservation areas were defined but not enforced in practice or in an obligatory approach. Additionally, the lack of communication between the community and government on policy management and implementation (FAO 1980) only made matters worse in the destruction of national forests possibly to the point of no return.

Presently there have been no clear solutions presented for the reformation of damaged forest or to prevent further encroachment of the forest. The government's position on policy implementation remains unclear, specifically regarding RFD which is the leading organization employed under the government forestry mandate. One avenue of approach for an appropriate solution to forest encroachment is for RFD to realize the importance of the issues, prioritize those issues and strictly define policy goals. Utilizing tools of law enforcement in addition to specifying and abiding by guidelines in a clear manner will create a strong foundation based on a strict code of conduct, employing ethical standards and transparency. If the policy implementation remains inefficient it will as it has been, ineffective, causing yet more degradation of the forest to escalate into a full blown crisis. (Environmental Investigation Agency, 2001)

From the information above, we can conclude that Pha Khao Phuluangs' problems originated from the RFD's lack of street level law enforcement and weak policy implementation. The manner in which they approached enforcement has blemished the area in such a way that the actual forest is in a state of constant decline. RFD must put forth a concentrated and committed effort to create a stronger and healthier policy implementation on forest protection and conservation. For a sustainable forestry conservation policy to be created and implemented an in-depth study is required utilizing the problems and inconsistencies directly resulting from content and poor implementation of past and present policies as a valuable tool of "lessons learned." The framework of the study should contain but not limited to:

1) Goal Attainment-Define organizational goals;

2) Adaptation-Resource study within the organization;

3) Integration-Create a healthier policy implementation under the organizations existing resources;

4) Latency- A maintenance approach to policy implementation in a way which allows the developmental process to become ethical standards of profession or "Code of Conduct" in order to achieve a structure and solutions acceptable to all parties involved.

A study on the topic of the policy implementation in Pha Khao Phuluangis absolutely necessary as it is vital to correct the injustices of forest encroachment and to amend the ambiguous regulation involved in the policy implementation including some deceptive but practical measures which lead to its airing mechanism in order to further develop and reform RFD in the very near future (Tracking Department of Forestry, 2012).

As mentioned above, Pha Khao Phuluang is a good example to use as a case in order to analyze the root of the problems in RFD's policy implementation and their law enforcement aspect in order to protect and preserve the remainder of the forest in the area. This study is based on AGIL structural and functional theory of Talcott Parsons (Parsons, 1937) which was further developed by Fremont James Lyden in 1975 with an intention to be used to describe the structural problems of policy implementation. AGIL will benefit the study by means of its complexity reduction and its unit of analysis simplification. Therefore, the key to the policy implementation improvement will be disclosure in order to protect and preserve the forest in a sustainable manner resulting in healthier change over the conflicted situations. The purpose of the study is to discover possible ways to alleviate the problem ultimately benefiting the forest resources and the environmental conservation in association with Social Structural Theory that has intentions to: 1) maintain the morale of the forest worker with accuracy and integrity 2) engage the fairness to all government agencies, and 3) protect and preserve forest resources in 
sustainable manner.

\section{Method}

Talcott Parsons' Social Functional Theory and analysis by Lyden when properly adapted to fit RFDs' policy implementation, will analyze and understand the problems of its organization resulting in proactive ways to protect and preserve the forest in Pha Khao Phuluang. The theoretical AGIL model could make conducting research more evident by looking at the structural and functional basic features of the analysis process. The study performed as a keyword case study method to its analysis as rationing from its upward features, which are:

1) The typical case which would draw out the Tacit Knowledge available within

2) The set of units that is able to represent the facts of ongoing occurrences of problems in/with theforest (Platt, 1992).

Therefore, the case of Pha Khao Phuluang is selected to represent the study because its conditions are consistent with the proposed problem. Studies have indicated that Pha Khao Phuluang's selection is ideal for use in a representation of Talcott's AGIL model and is additionally supported by the following perimeters:

1) Trial affects-suppression officers unjust;

2) Possible law suit is under consideration with extensive dialogue;

3) Case continues to cause concerns to the public in regards to its problematic law enforcement;

4) Case is ongoing within the justice system;

5) Case best reflects public forest intrusion (RFD, 2011).

To ensure accuracy, the study consisted of a group of 10 experts on the subjects of but not limited to; forest degradation, rebuilding, social aspects concerning integration of laws and natural resources. (Tashakkori \& Cresswell, 2007).

\section{Results}

\subsection{General Information of Pha Khao Phuluang}

Pha Khao Phuluang is a small district, officially located in the district of Amphoe Wangnamkaew, established on April 1, 1992. Pha Khao Phuluang encompasses a land area about 706,243 rais, which is divided into 5 tambon (township or sub district) and 83villages, with an approximate population of 50,000 people. The original community settlement of Pha Khao Phuluang was established in 1947 in accordance with the past Thai government forest concession policy. Enacting on the Economic and Social Development plans for the period, the government promoted a cultivation of cash crops, thus transforming the area of Pha Khao Phuluang from a forested mountain range into land that is now overexploited, and plagued with deforestation. Until 1987 there was no requirement for a forest reservation measurement, at that time private sectors and community organizations started to carry on forest reconstruction in Thasai and Kowpangma moo baan. In 1997, Pha Khao Phuluang community started a Tonnummoon watershed restoration project; recovering forest area back to a green, rich watershed. The community transformed the areas popularity both locally and nationally for its eco-tourism industry. This change created a new socio-economic context over the Pha Khao Phuluang area; lifestyles changed from agriculture to tourism. The government implemented a policy replacement to fit a promotion of tourism. (The Board of Trustees of Urban Development and civilian participation, 2011)

The allocated deteriorated forest land was done under the land reform act but never surveyed against military maps. The introduction of the National Park Act in 1981, which originated from the National Park Act of 1961, the Agricultural Land Reform Office investigated and found that 1,000 rais of the Agricultural Land Reforms Office's title deeds (ALRO 4-01) were allotted and out zoned deteriorated forest for the settlement of national forest reserves. In 1995 the cabinet resolution was supportive to withdraw the ALRO 4-01 which overlapped into the area of zone $\mathrm{C}$ or imposing on other laws.

The problems within Pha Khao Phuluang today reflects the controversial issue of RFD's legal enforcement which originated from a top down policy implementation regarding the plotting of reservation areas on the map without actual area inspection. This neglect affected the social equity and justice within the community in Pha Khao Phuluang. Conflict arose when the cabinet resolutions in accordance with ALRO 4-01to provide title deeds to squatters by not checking the actual areas as to whether the land was actually deteriorated. The central government's policy begs to question why the government implements a policy without inspecting and questioning the social and economic history of the area. This has turned the focal point of the impact on the social system in Pha Khao Phuluang which is encouraging the change of cultural and social system of the local 
community. (The Board of Trustees of urban development and the participation of the civilian, 2011)

The conditions in which officials enforced the laws in Pha Khao Phuluang reflect the character of the AGIL social system which stated "the social systems essence of survival has somehow related to social control with an intention to survive or maintain equilibrium in the society respectively to its environment." (Bennetta Jules-Rosette, 1980) Using socialism to some degree as a significant mechanism in the adaptation of new rules and regulations, the community would have to adapt themselves to the changing of their environment. Therefore, the Pha Khao Phuluang model of officials relies on legal enforcement of the laws to control community behavior In the beginning of the new rules implementation and transition the community showed signs of intolerance and resistance, once the law was fully implemented the community became confrontational. As a note; when rules existed in a rudimentary form the community desired to be included to negotiate terms.

Drawing from the AGIL's social structurally conceptual scheme in comparison to the social structure of Pha Khao Phuluang, it reflects that this area has been actually transformed from communist party base into a present day community of capitalistic tourism. In the past the government attempted to eliminate the communist alliance by creating a community from a logging concession policy, the government attempted to make substantial contributions to the economic growth over the area as a whole by promoting economic cash crops such as corn and sugarcane as these crops thrive in essentially bare land. In spite of this the land continued to deteriorate, eroding, devoid of nutrition. As more people moved into the area, ideals changed, a capitalists' vision of beautiful landscape along with a suitable climate purchased land from tenures, transformed the area into resorts and hotels creating new economics and social conditions in Pha Khao Phuluang. For the community's economical state, it meant jobs due to the growing tourism. The government stepped into assist in support of eco-tourism. ALRO 4-01 title deeds converted to sale and transferred holder rights of farmers to the capitalists. Past governments used populist policies as a tool to get votes by handing out ALRO 4-01 to the landlessness. ALRO 4-01 then re-distributed its responsibilities to various agencies such as RFD and the Agricultural Land Reforms Office to make recommendations and criteria for allocating land to squatters. Over time ALRO 4-01 was out zoned to deteriorated forest criteria (Zone A) into the settlement of national forest reserves (Zone C) by incident. This situation was the backbone of the government's land policy on forest encroachment into Zone C, which later created flooding and landslide problems in the area. In 1995, the cabinet passed a resolution to withdraw and disqualify ALRO 4-01 titles that overlapped Zone $\mathrm{C}$ areas with an intention of giving the land to RFD. From the cabinet resolution, RFD had to strictly enforce and exercise the power of the law under Section 25 to remove accommodations and construction in Zone $\mathrm{C}$ areas. This state of affairs created a new phenomenon in Pha Khao Phuluang, in the beginning the community was resistant to law enforcement using the show of weapons as intimidation then invaded state property. Law enforcement drastically changed the socio-economic conditions impacting community employment opportunities thus creating an immense distrust between governmental authorities and the local community. Until now reactions by locals have posted the model of social system that reflects the symbol of resistance to officials. Locals protested law enforcement and displayed their unacceptance of paying estate and forest taxes. Inevitably locals concede to law enforcement pressure, moving forward through the next step of cultural change in which the locals tend to negotiate with the government and authorities in order to safeguard some of their collective interests with the idea and hopes of returning to the forest buffer zone of the early 2000's. This circumstance in reference to the locals can be identified as, "pay it forward" into another stage of the social system, the attempt to interact between private and public for common interests defined as a representation of a new phenomenon of community negotiations in transition to a social equilibrium regarding the AGIL model.

\subsection{Results from Expert Discussion}

Parsons's social structural theory proposed that traditions and social customs are one of the major problems confronting the social system. The tradition often represents an agreement that was generated with an intention to protect universal rules existing over time. Yet, it is still intellectually doubted whether Parsons accepted or not that the social tradition actually effects the human social system. However, his point of views also illustrate that human behavior can also cause inter-personal relationships within the social system. This inter-personal relations can create personal roles on society at the same time it was determined by institutionalization that prototype the individual behaviors. Therefore, minimum requirements for a social system are the interaction of at least two personal systems or two persons acting in their roles. The roles are abstract features that regulate human relationships. Thus, individuals are believed that they have typically had a clear process to reflect human relationships logically as partners in their social relationship. Consequently, individuals also have behaviors that typically reflected to their tradition of governing their roles in order to fulfill their protagonists in society. Yet, an individual can also multiply various roles in one person in which Parsons interprets that if the individual has 
self-explanation, he would answer that question by describing his role in society. So, individuals need to fulfill their functions in society while relating themselves to their social structure. And, this is the nature of individual functions in society that can create equilibrium over their social system.

Parsons' perspective can somehow reflect the social context that can concepts experts' point of view over the problem of officials' legal enforcement in Pha Khao Phuluang. As protagonists the experts also upheld their beliefs to protect the common interests. Therefore, experts need to be under the social context that defends the common interest for the society, so they must adhere to universal rules to be neutral and acceptable by all stakeholders. As a result, experts uphold the interests involving the collective benefit compromising with all parties, either a group of government officials or villagers. Accordingly, the problem status from experts is set up with the mindset of problems that link these two groups such as the problems of cooperation or lack thereof between agencies involved, problems of budgets and resource deficits and problems of discretion over official's law enforcement. Therefore, Pha Khao Phuluang, according to the experts point of view, must occupy multiple roles in one single individual, so that the problem must have a solution for all parties involved which could make society back into a state of equilibrium again.

\subsection{Results From Authority's Discussion}

Parsons produced major theoretical statements that human social context can affect an individuals' action. Social context can identify individual status and represent the choice of actions as defined by the individual. The idea of this interactive situation between individual statuses will systematically form the most basic premise of their collective status persistently until their social system is in shape. On the same token, while the social systems are repeated functions as patterns of social systems will certainly form up their culture system. These patterns of social systems will paternally try to avoid unsystematic configuration. Yet, if the pattern of social system forms up to force others to their impossible action then, it may cause aberrant behavior and issues a conflict in human society.

From the Parsons subscriber, RFD officials' social context has been changing depended on the input factors of each period of dynamic governmental policies function. Dissimilar governmental policy and political context can define a new paradigm of social context to RFD officials'. For instance, the former government passed a cabinet resolution on anti- communism policy, therefore the government defined a new paradigm to officials who carry out and enforce the actions required by laws to switch their power to a first priority of responsibilities on anti-communism instead of forest protection. Although, the official duty is particularly required by law to protect and preserve the forest daily but authorities on their discretion decide what ought to be done or not. Rule and regulation create more discretion in professional attribute, an officials power is something that can limited as identified by law. Past culture context provided by the government was to diminish Communism, at the same time an ambiguous loophole in the rules of the state forests' line boundary left interpretation for the official at his discretion to ignore or enforce forest encroachment between the buffer areas in order to maintain social structure equilibrium. Consequently, past interactive behavior and social relationships between officials and locals, assisting and depending on each other in resource usage was the bases for legal enforcement. Locals were persistently informing the officers about forest invasion in the area of Pha Khao Phuluang, however, the current situation and new cultural context of policy, changes officials beliefs and interaction with people in a negative way especially with those who go against policies and rules along with prejudices of street-level bureaucrats who influence their treatment of citizens. Anti-forest encroachment became a necessary functional requisite to the official practice. This social context forced communities to take actions like disobeying law enforcement and deviations of their behavior into resistance which created conflicts between officials and locals, posed a problem of resource scarcity with the Royal Forest Department and formed problems of participation and coordination between agencies in Pha Khao Phuluang.

\subsection{The Villager's Discussion}

Parsons criticized that "institutionalization" is both a process and structure in which different background actors get into a social relationship. When actors have been actually institutionalized they will be met by adopting a new pattern of culture until it reaches the point that the social norms are formed while these norms were being refined into a certain culture. The norms over time become a cultural melting pot In order to control the inter-personal action with results of social stability in the end.

From Parsons' viewpoint, comparing Pha Khao Phuluang issues shows that when new legal enforcement was introduced, the need became essential for locals to adapt to the new cultural system that conflicted with the locals' former interests such as unjust legal enforcement of Section 25 along with ambiguous forest boundary lines. Showing issues of adopting a new culture that contrasts the former emerged as a positive for the 
community in employment opportunities in tourism. In the past, primary source of income was dependent on forest resources which sustained their way of life. With economic prosperity in Pha Khao Phuluang immigrant settlements continued from Chonburi, Prachinburi and other parts of eastern Thailand. Deforestation presented locals with another lifestyle change requiring the need for adaptation, from farm land to resorts and hotels. This living paradigm emerged a cultural melting pot encompassing new economic and social cultures over the tourism context contributing to a new social norm of living with the forest, taking initiative and becoming cooperative to take corrective action over the forest cooperation from the locals assisting authorities, like lending boats to catch offenders or informing authorities about encroachment. These actions became a culture to locals, protecting their forests due to a sense of ownership over forest restoration projects. However, when officials began enforcement upon the locals this caused serious grounding parallel factors as described in Parsons Theory forcing the locals to choose whether to take action as a collective or private interest. In other words they have to decide whether to act on universal regulation or on their own subjective discretion. At the moment, the community of Pha Khao Phuluang is still in a transitional period between universal regulation and their subjective discretion by negotiation between the two. For example, requesting benefits from the boundary line of 2000 or reshaping the area into a disclaimer of sorts.

\section{Discussion}

\subsection{Goal Attainment}

Considering the AGIL model to analyze organization, Lyden (1975) revealed that organizations have to work accordingly to society expectation with an intention to achieve social goals defined by external society. The society expectation is the organization's goals that can be interpreted as a decision making in four topics (Parsons, 1995):

1) Policy Decision-is the decisions on organizational goals;

2) Allocative Decision-is to decide on the organizations' resource allocation;

3) Coordination Decision-is to convince authorities within the organization toward organizational goals;

4) Supportive Values-is the value, regulation and legitimacy en route for validity and legitimacy decisive establishment in the organizational system.

Yet, either individuals or political parties who made the decisions need to decide whether to weigh their choices between those 4 variables in order to define proper goals in making organizational systems run in equilibrium.

Using AGIL for organizational analysis, the study found that organizational analysis is particularly different from any other forms of social systems. The social system analysis in general, may have a variety of goal attainment. Organization is merely trying to achieve a specific purpose, so the goal attainment illustrated in this research is merely a problem policy implementation goals definition determined by social expectations in order to solve the problems of this society.

Subscribing to the concept of AGIL, the study found that groups of experts, officials and villagers during the early stages of the conference was focusing on the goal of nominalist in creating a way for society and the economy to survive, most people proposed their conditions was for the government to freeze enforcement of Section 25 and receiving title deeds on behalf of people living in the forest before 1998. Officials weighed heavily on issues of legal enforcement and maintenance benefiting society as a whole. On the other hand, experts are on behalf of both sides by linking the government and the private target with the intention to maintain common resources for mutual benefits, with the condition that locals are able to accept it.

A common analogy of Parsons demonstrates that "goal attainment" is a mechanism motivating social decisions into changing the output. Pitched in the study, all three parties have concluded a sharing of goal attainment to their new paradigm of Pha Khao Phuluang culture system. The challenge of the three parties; to induce their productivity into the same definition. Villagers and officials have more interaction over the discussion as a result of their collective goals in responding to public demand. Therefore, at the final stage of discussion the problems agreement is met in order to meet the mutual interests in a collective manner which is to preserve the forest resource sustainably.

\subsection{Adaptation}

As the result of the goal attainment stated above; to point out that when the mutual target has changed (Goal Attainment), the decision making on the matter considering the problem statement of Pha Khao Phuluang has changed as well. As "goal attainment" is reached, the ability to move forward in conservation for the mutual benefit of society over sustainable forest management. During the first stage of the conference, locals were 
willing to focus on problems in the enforcement of Section 25 and the vagueness definition of Zone $\mathrm{C}$ area, in the second stage of the conference locals returned to focus on communication issues between officials and the community in reference to correct forest boundary lines, while officials changed their perception of the issues from a restrictive law enforcement into the problems of locals' consciousness to sustainable forest management over the area of Pha Khao Phuluang.

As seen in the study the problem of Pha Khao Phuluang originated from the following factors; government ambiguous policy and leaving its implementation in a fragmentary basis. Various agencies have taken actions to implement the policy while its implementation was still in an ongoing basis, leaving it to state officials' discretion in determining the need for law enforcement. Therefore, the responsibility for its implementation is not consistent with goals of the policy which commits to conserve the forest resources in line with the local economic and social structure.

It can be concluded that the ambiguity stated above is the origination of the issue that formed into a social conflict between locals and officials. For transparency, communications of information between both parties while implementing policy with social systemic understanding, the RFD's implementation must consider community history and social context using referendums as a mechanical tool. Without The community alignment, it can cause the community to be uncooperative to the implementation, create enforcement resistant which is unacceptable to the officials' regimes. Therefore, the state must sustain its main goal by preserving the natural resources along with maintaining the social structure context in the region. If the government policy implementation has the local's cooperation, issues will be eliminated because it has public recognition and acknowledgement. RFD will save resources and personnel to meet policy goals in the final stage of policy implementation.

During the development of Parsons' social structural system idea, he created "Pattern Variables", which are the normative variables, variable or concept that categorized the feature of social systems property. The "Pattern of Variables" used to classify the "Modes of Orientation" within individual, cultural and normative systems of the society. Pattern of Variable series are generated through a pair of variables which have opposite characteristics. Therefore, when analyzed, individuals decision making by using the pattern of variables, we can classify their actions laterally with individuals' role expectations such as the pattern of variable on emotional action or satisficed situation as well as the pattern of variable of inter-people relation of either mutual or private benefit.

As seen on Parsons' social structural systems, the pattern of variables control social norms that governs and control individuals' decision making at all levels of thought. Hence, individuals and social systems function as a reflection of cultural systems. Parsons tries to answer how individuals system can integrate into the social system bringing the society into equilibrium again. And the answer of his question is 2 mechanisms which are socialization and social control in order to help society in achieving its "Goal Attainment". The socialization would influence individuals system for them to integrate with the social system while the social control can reduce the individuals' role regarding to their status once they have been categorized into the social system. When social tension was deviated, the society will be in equilibrium stage again. Parsons admitted that if socialization fails, it could lead to the diversion of social change which is necessary to enable the balance in society.

One facet of Parsons Theory, society seems to be an organic mechanism that has various parts that interrelated and inter-supported to each other. The constant relationship of the organs in a social system is a factor that makes systems through social equilibrium. Another facet, are social changes, meaning that the social element becomes imbalanced; the three social elements; Organic Systems, Personal System and Cultural System. The social element is cracked for example, when there is a concern of war or new social culture. This causes tension within social structural units, so the change will systematically react through the whole system.

From the Parsons' stand point, it can reflect solutions of the locals, officials and experts toward Pha Khao Phuluang issues. His pattern of variables can influence all three parties decision under their part of organic mechanism, standing for each of their status will cause Pha Khao Phuluang to transition to a new cultural system. This transition contributes to social equilibrium within the community in the end.

\section{Conclusion}

The summary results of meetings between officials' experts and villagers on the Goal Attainment; they all agreed that the priority for the goal attainment is to conserve forest resources and ecosystems within the community. In order to achieve such goals, RFD should have a long-term policy planning in order to allocate corporate power in associated organization with its policy implementation, to correctly contribute to the continuity and consistency of its policy implementation while the policy formulation must also take into account factors that are 
contributing to the cycle of social and economic development of the community. RFD problems of today are caused by the inconsistency between government policy enforcement and socio-economic conditions within the community. RFD has no long-term policy planning that can support tourism within the district in the first phase. The department gave ALRO4-01 to others over the areas that should be public watershed. So when the government planned to recall the property and revoke community rights the locals socio-economic turned into violence and instability. To fix the problems, the government must give more time to acquire new land, and for community rehabilitation and adjustments to the economic and social conditions within the community. The government should also offer policies in order to support economic and social changes as a supplementary opportunity for a period of time under the ecosystems conservation context.

Politics undeniably influence changes in government policies which can affect the RFD's policy implementation. Reshape policy or the revocation of title deed shad a significant result to pressure the performance of Forestry Department officials. With limited resources and unavailable technology, RFD authorities perform their workload with discretion and available manpower. Therefore, their law enforcement operations and work production is inevitably inefficient, so politics has the potential for continuity and stability but must be watched for illegality.

\section{Recommendation}

\subsection{Integration}

It can be stated, the essence of Parsons' social systems is socialization and social control. The socialization is a mechanism adopting human moral and regulation. However, Parsons has never mentioned about an absolute or perfect society, while the society development is merely another step to its social system. As perceived by Parsons, humans act on a voluntary basis in order to respond to its society phenomena and institutions as their preference expectation. Therefore, another step of society development could lead to both a negative and positive impact over human behavior, so it is very necessary to rule both unofficially and officially on those behaviors such as gossiping, regulation and so on. When formal rules are fixed and stabled, these rules are absolutely to control society. The relationship of the individual to the situation, are always in a form of various negotiation. When human roles were created, they will build a model of human tradition in order to guide action in the right direction. Human initialization was created to stabilize human social relationships. This model is called the transition to equilibrium.

Using Parsons' theory in reflecting the issues of Pha Khao Phuluang, policy implementation problems resulted in the ideal that the government had to identify its goal attainment clearly in order to encourage collaboration between the involving agencies and authorities; Identifying issues from bottom-up and assessing policy impact of target groups by the government solution. Concluding, all three parties' goal attainment changed from its beginning of using 2000's forest boundary line into the mutual benefit over forest management.

However, when authorities faced limitations in terms of resources and personal, discretion of resource usage was considered depending on politics and policy constraints. Inevitably, the success of policy implementation over Pha Khao Phuluang is depended on the clarity and conciseness of the policy. At the same token, proper public and political support for the policy in the long run in order to abide the policy action in the right direction.

In Pha Khao Phuluang, key factors linking the community's transitions into their new goal attainment is the communication between the community and government. The new community role was created when all parties exchanged information clearly and accurately through negotiations. The local who lost those benefits from the forest boundary line, were those who were fighting for forest mutual benefits, a melting pot for a common forest owners. The communicative mechanism will cause conservative moral and transition to their new culture to create the mutual possessor sentiment into the Pha Khao Phuluang community. These processes can stabilize the society through all parties' communication and social relationships.

\subsection{Latency}

Parsons views that Latency creates sustainable solutions to problems until its solution finally becomes a Code of Conduct or professional practices. He suggests that all related stakeholders involved in the social system will stimulate social solution into Latency or pattern of maintenance. Finally, the exchange between adaptation and Latency will cause the output which may or may not be successful to the public in responding to the public expectations and satisfaction.

From the study, the three parties agree that in order to reach a sustainable stage in Pha Khao Phuluang the community and authorities have to raise awareness of forest conservation to both public and government officials and advocate both parties in partisan benefit. 
The significant essence to a sustainable forest management is that the officials must have forest conservative integrity and not fall under the influence of the elite. Currently, there are various media that can protect officials from elite influence at the same time officers must have a strong sense of morality and integrity as well as the modern technological tools which can also assist in their operations.

Moreover, all parties outlook is that it is currently a sufficient organization, both constitutional and with a think tank organization to monitor and or enforce the law. Other organizations should be set up as public hearing or social services organizations which study the public agenda and take it to the government for consideration. This organization should protect the officers rights against dark powers, therefore several parties must commit themselves to work together.

At present, the communism problem in Thailand has been overcome but the most important issue today is not the discontinuation of the Thai governmental policy implementation due to the shifting of the Minister of Agriculture which directly impacts the strategic policy objectives and policy implementation. Upcoming with the short-term government, the governments may have elite pressure causing a compromise or partiality in deviation of government practices that are illegitimate. This has made the government practice in each period continuing in same standard and unclear. Therefore, the three parties are coming up with solutions which the Royal Forest Department officials are abiding by. Ethics, integrity and pride in professionalism should never be wavered and influenced by others who benefit. Additionally, the shifting in minister of the Ministry of Natural Resources and Environmental Resources cannot place power to influence or change the officer's discretion if bureaucrats run continuous and straightforward which will support the officers' ability to maintain a forest environment.

However, independent and think tank organizations such as a forest protection organization, if benefits are involved will cause a rift in the organization. If these independent organizations establish themselves naturally, an unofficial surveillance unit is created that would correct undesired actions. Established organizations naturally, must start from a volunteer group such as Bison Conservative Group to convince people to volunteer, turning their income to ecotourism rather than income from hunting bison. It is important to raise awareness to the villagers for forest conservation, rather than illegal activities.

The key issue is to divide the forest zones, including rainforests into correct measurement, activities for people living in the area. RFD must raise awareness about forests and provide education about eco-farming. Motivating people in forest conservation is the serious work of the Royal Forest Officer when dealing with and engaging squatters. RFD officials when enforcing the law, government officials should check legal intention to decide whether people are guilty or not.

One of the issues baring authorities in enforcing the law is the discretion of law enforcement. Presently in Thailand the authorities have been making decisions based on capitalistic benefits. It is vitally important that RFD officer's help promote and assist officials' integrity to save the forest as their priority. If the officers are corrupt, the public should be encouraged to post a complaint in order to create awareness.

\section{Acknowledgments}

I would like to express the deepest appreciation to my committee chair professor, Assoc. Prof. Sirirat Choonhaklai, Chokchai Suttawet and Asst. Prof. Nopranue Sajjarax Dhirathiti, who have the attitude and substance of a genius to convince a spirit of adventure in regard to research and teaching. Without their guidance and persistent help, this dissertation would not have been possible.

\section{References}

Bennetta, J. R. (1980). Talcott Parsons and the Phenomenological Tradition in Sociology: An Unresolved Debate. Human Studies, 3, 311-330. http://dx.doi.org/10.1007/BF02331818

Environmental Investigation Agency. (2001). SUPER Act to Slow Global Climate Change. Bangkok: EIA.

FAO. (1980). Changes in land use in South and Southeast Asia from 1880 to 1980: A data base prepared as part of a coordinated research program on carbon fluxes in the tropics. USA: Elsevier.

FAO. (2003). FAO-Forestry profile-Thailand. Bangkok: FAO.

Lokeniyom, P. (2008). Measures to tackle the invasion of the national forest and woodland areas. Bangkok: The Royal Forest Department.

Lyden, F. J. (1975). Using Parsons' Functional Analysis in the Study of Public Organizations. Administrative Science Quarterly, 20(1), 55-70. America, Sage Publications. http://dx.doi.org/10.2307/2392123

Macionis, J. J., \& Gerber, L. M. (2010). Sociology, Seventh Canadian Edition with MySocLab. Canada: Pearson 
Education.

National Bureau. (2013). Statistical Geographic Information System 2013. Bangkok: Office Statistics Thailand.

Parsons, T. (1937). The Structure of Social Action. New York: Free Press.

Parsons, W. (1995). Public Policy: An Introduction to the Theory and Practice of Policy Analysis. Cambridge: University Press.

Platt, J. (1992). A Case Study in American Methodology Thought. USA: SAGE Social Science Collection.

RFD. (2011). Forestry statistics of Thailand 2011. The Royal Forest Department. Bangkok: Information Office.

Tashakkori, A., \& Creswell, J. (2007). Exploring the nature of research questions in mixed methods research. Journal of Mixed Methods Research, 1(3), 207-211. http://dx.doi.org/10.1177/1558689807302814

The Board of Trustees of Urban Development and civilian participation. (2011). PhaKhao-Phuluang Report. Bangkok: The Department of Trustees of Urban Development and civilian participation.

Tolstoy, T. (1896). War and Peace. USA: Elsevier.

Tongkham, S., \& Huttasarn, S. (2011). Proven in the case of forest and land rights the Law Reform Commission. The rule of environmental laws Project. Bangkok: Committee of Regulatory Reform.

Tracking Department of Forestry. (2012). The National Forest Assessment 2012. Department of Forestry Tracking, Bangkok: The Royal Forest Department.

Tracking Department of Forestry. (2013). The National Forest Assessment 2013. Department of Forestry Tracking. Bangkok: The Royal Forest Department.

Wananwijit, A. (2002). Biotechnology rice improvement in science and technology of Thailand. The National Center for Genetic Engineering and Biotechnology. National Science and Technology Development Agency, 79-121.

Wanapitak, P. (2013). Village forests. Horticulture Journal, 10(2), 43-47. Kasetsart University. Bangkok, Thailand.

\section{Copyrights}

Copyright for this article is retained by the author(s), with first publication rights granted to the journal.

This is an open-access article distributed under the terms and conditions of the Creative Commons Attribution license (http://creativecommons.org/licenses/by/3.0/). 